\title{
El turismo como promotor del desarrollo económico en las economías periféricas
}

Mg. Viviana Bercheñi (*)

Palabras claves: Turismo, desarrollo, sustentabilidad, competitividad.

\section{Introducción:}

La experiencia macroeconómica en las economías desarrolladas en general y en América Latina en particular ha sido signada por la incidencia recurrente de intensas fluctuaciones cíclicas, que fueron generadas por variaciones de variables clave, entre ellas la tasa de ahorro y la inversión pública y privada, el tipo de cambio, que iniciaron o culminaron procesos acumulativos, que condicionaron variaciones en las tasas de crecimiento en, al menos, los últimos setenta años. Ante un contexto internacional económico y político cambiante, la posibilidad de surgimiento de nuevas crisis sistémicas endógenas o importadas hace ineludible la identificación de políticas públicas que han condicionado el crecimiento económico de los últimos años, su relación causal con las teorías económicas aplicadas a tal efecto y su vinculación con el desarrollo potencial del Sector Turístico como promotor del desarrollo.

La globalización supuso un flujo internacional continuo de ideas y conoci-

mientos, intercambio cultural, sociedad civil global y movimiento global a favor del medio ambiente. Su gran esperanza fue brindar un fácil acceso de los países pobres a los mercados internacionales de manera que puedan vender sus productos, movilizar recursos y aspirar a una mejor calidad de vida.

Stiglitz aclara, sin embargo, que la globalización no ha podido cumplir su promesa de distribuir recursos para todo el mundo de manera equilibrada. La gran equivocación fue haber delegado en los países desarrollados la potestad de diseñar las reglas de juego conformando a la globalización en función de sus propios intereses. Su objetivo no ha sido crear reglas de juego justas ni a favor de intereses de países en vías de desarrollo.

La consecuencia directa de la globalización para estos países fue la profundización de la pobreza, interpretada por Kliksberg como el mayor dilema moral del planeta y el más grave delito contra los derechos humanos del siglo XXI. La globalización no acabó con ella y las crisis económicas desatadas como consecuencia de ella, no han hecho más que agudizarla.

(*) Facultad de Artes, Diseño y Ciencias de la Cultura. UNNE. e-mail: viviber@hotmail.com 
Particularmente la inserción internacional de América Latina en los mercados mundiales (1945 - 1955) ha sido causa del diseño de teorías vinculadas al desarrollo económico y social del bloque, a través de la teoría del estructuralismo latinoamericano que trataba de identificar estrategias de desarrollo económico y describir cómo podría un país en vías de desarrollo romper con el ciclo vicioso de la pobreza y comenzar a movilizar engranajes del desarrollo. Autores tales como Raúl Prebisch, Aldo Ferrer, Celso Furtado, Fernando Cardozo entre otros, analizan el desarrollo latinoamericano desde sus deficiencias estructurales y la influencia que tienen sobre este proceso, sus inadecuadas estructuras políticas, sociales, internacionales en las relaciones centroperiferia que condicionan el mercado y la producción real. En este sentido, esta teoría sustenta la posibilidad de la autodeterminación de las economías periféricas en cuanto al diseño de políticas públicas que se orienten al desarrollo propio potenciando su desarrollo turístico y demás sectores priorizados, y desde esta perspectiva, el aporte del turismo concebido como actividad promotora del desarrollo en economías periféricas que como características comunes presentan gran disponibilidad y diversidad de recursos naturales, oferta laboral abundante, mercado interno consolidado, ofrece una alternativa superadora, que movilizaría inversiones públicas y privadas, promovería y diversificaría el consumo, generaría empleos directos e indirectos, contribuiría a la redistribución de la renta en tanto y en cuanto el diseño de políticas públicas que organicen su desem- peño se basen en la defensa de los intereses propios de dichas economías periféricas.

En este sentido, la presión tributaria, el tipo de cambio real y el saldo de la Balanza comercial definirían la competitividad de esta actividad económica con respecto al resto del mundo.

\section{Objetivo General:}

Analizar el tipo de cambio real y la presión impositiva como elementos condicionantes de la competitividad en el desarrollo del sector turístico.

\section{Hipótesis de Investigación:}

La presión impositiva y el tipo de cambio real encarecen los productos turísticos nacionales y quita competitividad al Sector.

\section{Metodología:}

Se cuantificó el impacto de la presión tributaria y el tipo de cambio real en la competitividad del Sector turístico analizando la evolución de la presión tributaria en relación al saldo de la Balanza Turística en el período 1990 - 2001 y 2003 - 2009 en base a la evolución del tipo de cambio real en igual período recurriendo a fuentes primarias y secundarias de organismos oficiales. Simultáneamente se evaluó y analizó la evolución del turismo receptivo, el gasto turístico y el tipo de cambio real vigentes para las mismas etapas.

\section{Resultados:}

Si bien la mayor presión impositiva incrementa el precio de los productos internos, el Gasto Público bien orientado puede 
contribuir a reducirlos: Por ejemplo, si tomamos como ejemplo los subsidios orientados a reducir el precio interno de la energía que se asigna a las industrias, esto implica una reducción de sus costos de producción. Al mismo tiempo, si la mayor presión impositiva se produce como resultado de un incremento en los derechos de exportación de bienes primarios, ello abarata el precio de los insumos de la industria nacional.

Para poder medir razonablemente el impacto de la presión tributaria y tipo de cambio real en lo atinente a la competitividad del Sector Turístico, se muestran los resultados en los siguientes períodos:

Período 1990 - 2001: En esta etapa la presión impositiva promedio aproximada alcanzaba un 20\%. El tipo de cambio real fue relativamente bajo, el saldo de la Balanza Comercial deficitaria y un crecimiento económico promedio ubicado en el orden del 6\%. La Balanza turística fue deficitaria en la mayoría de los años observados.

Período 2003 - 2015: En esta etapa la presión impositiva promedio alcanzaba un 30\%. El tipo de cambio real fue relati- vamente alto, la Balanza Comercial superavitaria y un crecimiento económico promedio ubicado en el orden del 7\%. E1 resultado de la Balanza turística fue positiva para los años 2006 a 2008 y 2010 y deficitaria para el resto del período considerado, aunque el desempeño externo en turismo fue significativamente mejor que en el período anterior.

Si tomamos por competitividad los precios de los paquetes turísticos comparados con los de otros países, tomando como ejemplo la relación con Brasil, vemos que en la primera etapa nuestro país era más caro. En la segunda etapa más barato. En la primera etapa, el crecimiento del Producto Bruto Interno vino inexorablemente acompañado por un déficit de la Balanza Comercial. En cambio, en la segunda, el crecimiento se dio en la mayoría de los años con superávit de la $\mathrm{Ba}$ lanza comercial. E1 desempeño comercial y el mayor valor del tipo de cambio real de la segunda etapa singaron su desarrollo y un mejor desempeño externo en servicios turísticos.

Cuadro No1: Evolución del Turismo receptor período 1990 - 2009

\begin{tabular}{|c|r|r|c|}
\hline Año & \multicolumn{1}{|l|}{$\begin{array}{l}\text { Total de } \\
\text { arribos }\end{array}$} & \multicolumn{1}{c|}{ Brasil } & $\begin{array}{c}\text { Gasto Total } \\
\text { millones de } \\
\text { USS }\end{array}$ \\
\hline 1990 & 1.930 .034 & 246.712 & $\$ 1.130,90$ \\
\hline 2000 & 2.909 .468 & 451.368 & $\$ 2.817,00$ \\
\hline 2003 & 2.995 .272 & 350.298 & $\$ 1.942,00$ \\
\hline 2009 & 4.292 .326 & 721.283 & $\$ 3.792,00$ \\
\hline
\end{tabular}

Fuente: Ferreres O (2011) Dos Siglos de Economía Argentina. Pág. 522. 
Cuadro No2: Evolución del Tipo de cambio real bilateral deflactado por IPC.

\$/US\$ de 2009.

\begin{tabular}{|c|c|}
\hline Año & $\begin{array}{c}\text { Tipo de cambio } \\
\text { real bilateral } \\
\text { deflactado por } \\
\text { IPC }\end{array}$ \\
\hline 1990 & $\$ 3,673$ \\
\hline 2000 & $\$ 2,324$ \\
\hline 2003 & $\$ 5,197$ \\
\hline 2009 & $\$ 3,734$ \\
\hline
\end{tabular}

Fuente: Ferreres O (2011) Dos Siglos de Economía Argentina. Pág. 673.

Cuadro No3: Balanza de la Cuenta Servicios: Ingresos y egresos por viajes en millones de US\$.

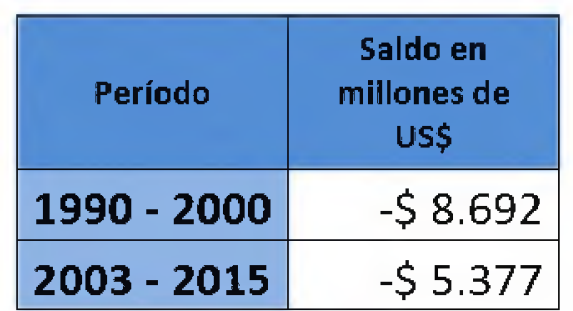

Fuente: Instituto de Estadística y Censos.

Los tipos de cambio de moneda están sujetos a diferentes variables de orden político o económico, en función de la $\mathrm{Ba}-$ lanza Comercial. Desde la óptica del turismo internacional, el turismo receptivo es un concepto económico de exportación de bienes, servicios y capitales, puesto que genera un ingreso de divisas en los países receptores, mientras que el turismo emisor es una importación, ya que la salida de los nacionales de un país al extranjero conlleva la compra por éstos de bienes y servicios en el exterior y consecuente- mente un gasto de divisas. La devaluación de la moneda local si bien favorece el turismo extranjero hacia el país, suele estar acompañada de otros factores de influencia, introduciéndose un elemento de complejidad ya que a su vez se verá condicionada por la evolución de los precios internos y el crecimiento económico.

Por ende y en función de análisis antecedentes, tiene mayor incidencia el tipo de cambio real que la presión impositiva en el nivel de competitividad alcanzada por el Sector Turístico Nacional. 


\section{Bibliografia}

a. Kliksberg B. (2006) Más ética más desarro1lo. Buenos Aires. Temas Grupo Editorial. 14 ava edición.

b. Kliksberb B (1993) Pobreza: Un tema impostergable. Nuevas respuestas a nivel mundial. México, D.F. Fondo de Cultura Económica. Primera edición. c. Mota Díaz, L. (2005). Reseña de "Más ética, más desarrollo" de Bernardo Kliksberg. Convergencia. Revista de Ciencias Sociales, 12 (38), 413-421.

d. Stiglitz,J. E. (2010). El malestar en la globalización. Taurus. 